\title{
Intrathoracic migration of a breast prosthesis after thoracotomy
}

\author{
Akash M. Mehta, MD, ${ }^{a}$ Martin P. L. Bard, MD, PhD, ${ }^{\mathrm{b}}$ Alexander van Straten, MD, ${ }^{\mathrm{c}}$ Imko van Beijeren, MD, ${ }^{\mathrm{d}}$ and \\ Herman Rijna, MD, PhD, ${ }^{a}$ Haarlem, The Netherlands
}

丹 Supplemental material is available online.

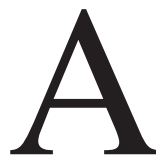

52-year-old woman was admitted to the Department of Pulmonary Medicine, Kennemer Hospital, after an elective lobectomy of the right upper pulmonary lobe with mediastinal lymph node dissection resulting from T1N0M0 non-small cell lung cancer. During this procedure, a right-sided muscle-sparing thoracotomy had been performed to gain entrance to the thoracic cavity. The medical history further revealed bilateral breast augmentation 14 years before the current admission.

The postoperative period was remarkable for continuous chyle leakage, which was treated conservatively with prolonged chest drainage and a fat-free diet. On the 12th postoperative day, the patient had progressive dyspnea. Physical examination demonstrated a breast volume asymmetry. Conventional radiography of the chest revealed a supraphrenically located density in the right thoracic cavity (Figure 1). Computed tomography of the chest demonstrated a silicone breast prosthesis in situ in the left breast and an empty subpectoral cavity in the right breast, with intratho-

From the Departments of Surgery, ${ }^{\mathrm{a}}$ Pulmonary Medicine, ${ }^{\mathrm{b}}$ Radiology, ${ }^{\mathrm{c}}$ and Anaesthesiology, ${ }^{\mathrm{d}}$ Kennemer Hospital, Haarlem, The Netherlands.

Received for publication July 21, 2007; revisions received Aug 31, 2007; accepted for publication Sept 13, 2007.

Address for reprints: A. M. Mehta, MD, Department of Surgery, Kennemer Hospital, P.O. Box 417, 2000 AK Haarlem, The Netherlands (E-mail: mehta@kg.nl).

J Thorac Cardiovasc Surg 2008;135:206-7

$0022-5223 / \$ 34.00$

Copyright @ $\odot 2008$ by The American Association for Thoracic Surgery doi:10.1016/j.jtcvs.2007.09.003 racic migration of the right silicone breast prosthesis through a 2.7 $\times 3.0-\mathrm{cm}$ defect in the right thoracic wall (Figure 2).

A rethoracotomy was performed, during which the breast prosthesis was found to be located on top of the right hemidiaphragm (Figure E1). During this procedure, the prosthesis was removed, the thoracic duct was clipped to prevent further chyle leakage and the thoracic wall defect was closed.

The patient was discharged 2 weeks after the second thoracotomy. At follow-up, a procedure to correct the visible asymmetry of the breasts was planned.

Post-thoracotomy intrathoracic migration of a breast prosthesis has not been described previously, although this migration has been reported after breast augmentation. ${ }^{1}$ Intrathoracic rupture of breast implants has also been reported after sternotomy and chest tube thoracostomy. ${ }^{2,3}$ In the case described herein, the posterior prosthesis capsule was partially opened during the initial thoracotomy; although specific attention was paid to adequate closure of the chest wall, it is conceivable that the negative intrathoracic pressure caused by prolonged post-thoracotomy chest tube drainage led to forced migration of the pliable silicone breast prosthesis through a gap between two sutures of the thoracotomy. This case underlines the need for meticulous closure of the chest wall after thoracotomy, especially in patients with breast implants, inasmuch as intrathoracic migration of prostheses can lead to significant patient discomfort and respiratory complications.

\section{References}

1. Chen ZY, Wang ZG, Kuang RX, Wang BT, Su YP. Implant found in thoracic cavity after breast augmentation. Plast Reconstr Surg. 2005; 116:1826-27.

2. Levine RL, Allen TC, Cartwright J Jr, Cagle PT. Silicone thorax due to a ruptured breast implant. Chest. 2005;127:1854-57.

3. Rice DC, Agasthian T, Clay RP, Deschamps C. Silicone thorax: a complication of tube thoracostomy in the presence of mammary implants. Ann Thorac Surg. 1995;60:1417-9. 

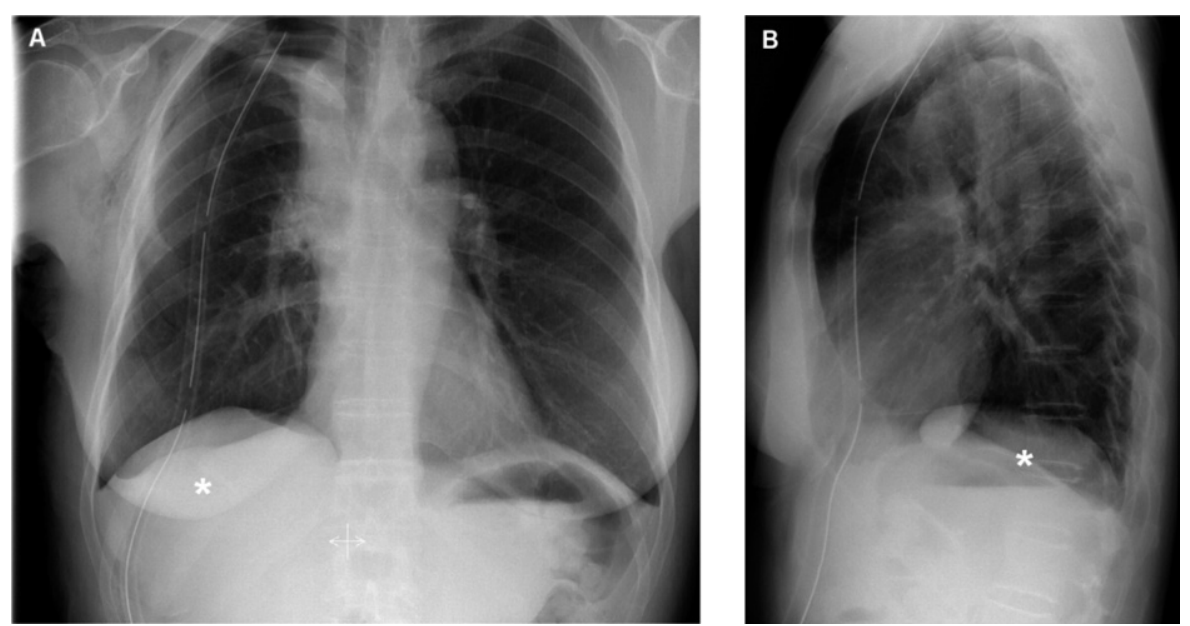

Figure 1. Posteroanterior (A) and lateral (B) radiograms showing a density on top of the right hemidiaphragm (asterisks).
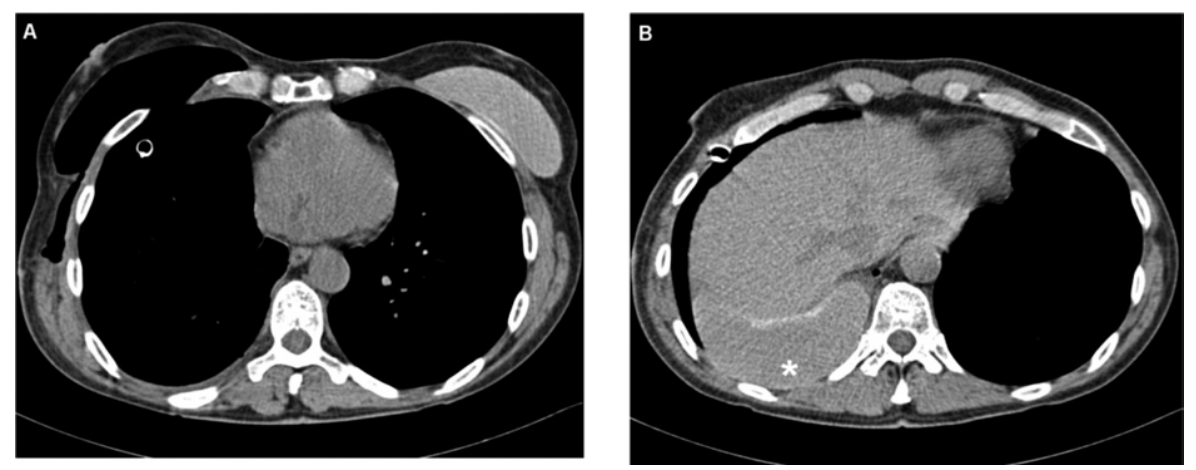

Figure 2. Computed tomographic scans of the chest: A, Absence of right-sided breast prosthesis, whereas the left-sided prosthesis is in situ; B, the prosthesis (indicated with an asterisk) is located dorsobasally in the right hemithorax. 


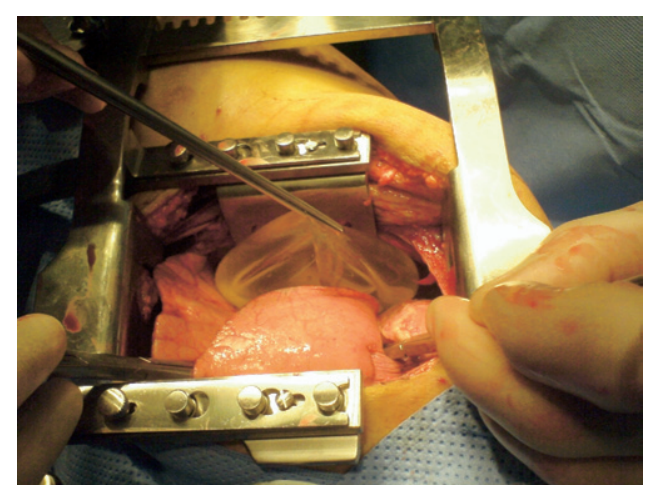

Figure E1. Intraoperative photograph showing intrathoracic location of the breast prosthesis caudal to the right lung. 